\title{
The effects of subconjunctival betamethasone on the blood aqueous barrier following cataract surgery: a double-blind randomised prospective study
}

\author{
S M Shah, J D McHugh, D J Spalton
}

\begin{abstract}
The aim of this double-blind randomised prospective study was to assess the effect of subconjunctival Betnesol (betamethasone sodium phosphate $0 \cdot 1 \%$ ) on the recovery of the blood aqueous barrier (BAB) following cataract surgery in uncomplicated eyes. Twenty patients [10 male, mean age 71.4 (SD 12.7) years] admitted for routine cataract surgery were randomised into two groups. All patients recruited into the study were free of other ocular disease and were not taking any anti-inflammatory medication. Group A received a subconjunctival injection of cefuroxime (125 mg) alone while group B received a subconjunctival injection of both cefuroxime and Betnesol. All surgery was performed by a single surgeon using a standardised surgical technique and all patients received the same postoperative medication. The Kowa laser flare cell meter was used to measure aqueous flare and cells preoperatively and on the first, second, and seventh postoperative day, and at 1 and 3 months following surgery. The code was broken only after all patients had been followed-up for 3 months postoperatively. There was no significant difference between the two groups in aqueous flare and cells at any of the postoperative visits. In this study we were unable to demonstrate any beneficial effect of subconjunctival betamethasone on damage to and recovery of the BAB following cataract surgery in the uncomplicated eye.

(Brf Ophthalmol 1992; 72: 475-478)
\end{abstract}

Many surgeons give an injection of subconjunctival steroids at the end of a cataract operation in the belief that it will produce a quieter eye postoperatively, with less damage to the blood aqueous barrier (BAB), a more rapid recovery of the eye, and a reduction in postoperative inflammatory complications. However, to the best of our knowledge, this has never been clinically proved. At present therefore some surgeons use subconjunctival steroids routinely in all cases, some not at all, and others use them only in selected high risk cases. The aim of this double-blind randomised prospective study was to assess the role of subconjunctival steroids in cataract surgery in the normal eye. Until recently the objective assessment of damage to the BAB has only been possible using anterior segment fluorophotometry. ${ }^{1}$ However this technique is invasive, time-consuming, and the results are often difficult to interpret. The laser flare cell meter is a recently introduced instrument that allows a rapid and non-invasive quantification of aqueous flare and cells by measurement of light scattering of a helium-neon (He-Ne) beam in the anterior chamber. ${ }^{2}$ The instrument has been shown to be highly accurate and reproducible ${ }^{3}$ and to compare favourably with fluorophotometry in assessment of damage to the $B A B$ following cataract surgery. ${ }^{4}$ We have used this instrument to document objectively the effect of subconjunctival betamethasone (Betnesol) on postoperative flare and cells.

\section{Materials and methods}

THE LASER FLARE CELL METER

The laser flare cell meter (Kowa FC 1000) consists of an He-Ne laser slit-lamp, a binocular microscope fitted with a photomultiplier and a personal computer. ${ }^{1}$ The $\mathrm{He}-\mathrm{Ne}$ beam has a power of $25 \mu \mathrm{W}$ and a diameter of $20 \mu \mathrm{m}$. The beam is projected into the anterior chamber and scattering of the beam within a sampling window $(0.3 \times 0.5 \mathrm{~mm})$ is detected by the photomultiplier. Two measurement modes are used, one for protein concentration and the other for cell count. The instrument automatically converts from one mode to the other. Each mode takes 0.5 seconds and thus the total measurement time is 1 second. Computer analysis distinguishes between photons reflected from cells or protein. In the protein concentration measurement mode the laser beam is scanned vertically for a length of $0.6 \mathrm{~mm}$, covering the sampling window. Scattering of this beam is measured when it passes through this window. Measurements are also taken when the beam passes above and below the sampling window to assess the background signal (BG1 and BG2). The flare value in photon counts $/ \mathrm{ms}$ is calculated by subtracting the signal value from a mean of two background counts. In the cell count mode the beam is scanned two dimensionally $(0.6 \times 0.25 \mathrm{~mm})$ in the sampling window and the scanning volume corresponds to $0.075 \mathrm{~mm}^{3}$. A strong peak of scattered light is obtained when the beam strikes a floating cell, and the number of peaks is counted by the computer.

Scans in which the difference between BG1 and BG2 exceeded $15 \%$ (indicative of a nonuniform background) were excluded and the scan repeated. To prevent 'massaging' of data, once the instrument had been aligned each sequential scan was accepted provided the difference between the background counts was less than $15 \%$. The results of five scans were then averaged. Laser flare cell measurements were 
performed preoperatively, and on the first, second, and seventh postoperative day and at 1 and 3 months following surgery.

\section{SUBJECTS}

Informed consent was obtained from all patients prior to the study. Twenty patients admitted to St Thomas' Hospital for routine cataract surgery were recruited for the study. All patients entered into the study were free of other ocular disease and were not taking any anti-inflammatory medication. Patients with systemic diseases known to affect the BAB (for example, diabetes) were also excluded from the study. The patients were then randomised on a double-blind basis into two groups (groups A and B). Patients in group A were allocated to receive a subconjunctival injection of cefuroxime $125 \mathrm{mg}$ alone while patients in group B were to receive a subconjunctival injection of both cefuroxime $125 \mathrm{mg}$ and Betnesol $(4 \mathrm{mg})$. The basis of allocation was known only to the surgeon, the code being broken after a 3 month follow-up had been completed on all patients. The surgeon was not involved in the postoperative assessment of the patients.

\section{SURGERY}

All surgery was performed by the same surgeon (JDM) using a standardised extracapsular surgical technique. At the completion of the procedure the surgeon was given the patient's code (group A or B) and the appropriate subconjunctival injection administered. Subconjunctival injections were administered transconjunctivally into the inferotemporal fornix. Postoperatively all patients received the same medication consisting of topical Maxitrol (dexamethasone $0.1 \%$ and neomycin $0.35 \%$ ) four times daily for the first week and twice daily for a further 3 weeks.

\section{STATISTICAL ANALYSIS}

Differences between the two groups in the

Table 1 Characteristics of patients in groups $A$ (no subconjunctival betamethasone) and $B$ (subconjunctival betamethasone)

\begin{tabular}{llll}
\hline & Group $A$ & Group $B$ & $p$ Value \\
\hline Age (years) & $69 \cdot 2 \pm 15 \cdot 7$ & $73 \cdot 6 \pm 7 \cdot 5$ & $0 \cdot 67$ \\
Sex male & $5 / 10$ & $5 / 10$ & $0 \cdot 65$ \\
Race Caucasian & $9 / 10$ & $9 / 10$ & $0 \cdot 46$ \\
$\begin{array}{l}\text { Iris colour } \\
\text { brown }\end{array}$ & $4 / 10$ & $3 / 10$ & $1 \cdot 0$ \\
\hline
\end{tabular}

The mean ages (SD) and distribution of sex, race, and iris colour in patients in groups A and B. (Group A: no subconjunctival betamethasone, group B: subconjunctival betamethasone.) The two groups were well matched for all these characteristics.

Table 2 Postoperative visual acuity

\begin{tabular}{lll}
\hline Visual acuity & $\begin{array}{l}\text { Group } A \\
(\mathrm{n}=10)\end{array}$ & $\begin{array}{l}\text { Group } B \\
(\mathrm{n}=10)\end{array}$ \\
\hline $6 / 5$ & 1 & 0 \\
$6 / 6$ & 2 & 6 \\
$6 / 9$ & 4 & 3 \\
$6 / 12$ & 2 & 1 \\
$6 / 18$ & 1 & 0 \\
\hline
\end{tabular}

The best corrected postoperative visual acuity at 3 months in groups A and B. (Group A: no subconjunctival betamethasone, group B: subconjunctival betamethasone). distribution of race, sex, and iris colour were analysed using the $\chi^{2}$ test. Laser flare and cell data were not normally distributed even after logarithmic transformation. Therefore differences in aqueous flare and cells between the two groups were analysed using the nonparametric Mann-Whitney test; $p$ values of less than 0.05 were considered to be statistically significant. All variables are presented as the mean (1 SD).

\section{Results}

Twenty patients (10 male, 18 Caucasian, mean age 71.4 (SD 12.7) years, range 34-90 years) were randomised to receive either a subconjunctival injection of cefuroxime and Betnesol or cefuroxime alone. The two groups were well matched in their distribution of age, sex, race, and iris colour (Table 1). There was no significant difference $(p=0.35)$ between the two groups in the distribution of best corrected visual acuity at 3 months following surgery with over $90 \%$ of patients in each group achieving a visual acuity of $6 / 12$ or better (Table 2 ).

The changes in aqueous flare and cells following surgery are shown in Figure 1. There was a peak in aqueous flare and cells on the first postoperative day, followed by a rapid decline in the first week, with a more gradual return to normal levels by 3 months following surgery. There was no significant difference $(p>0.05)$ between the two groups in both flare and cells at any of the postoperative visits. On the first postoperative day there was also no difference between the two groups in the number of eyes
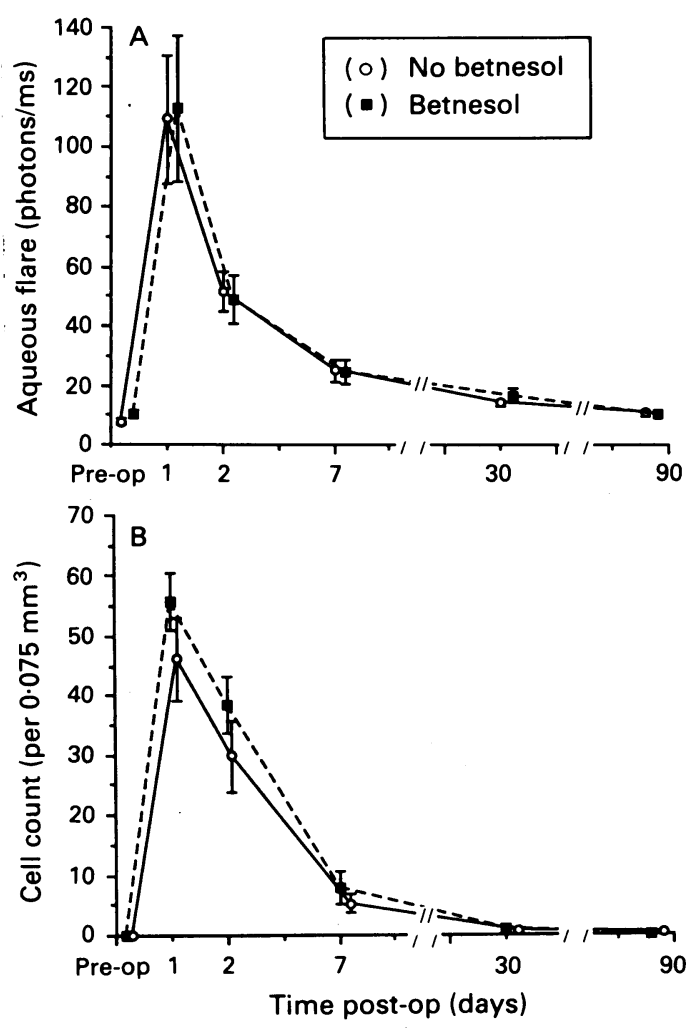

Figure 1 Changes in aqueous flare and cells following cataract surgery. Line plot of mean (SEM) aqueous flare $(A)$ and cells $(B)$ against days following surgery for groups $A$ and $B$. (Group A: no subconjunctival betamethasone, group $B$ : subconjunctival betamethasone.) 
(three eyes in each group) with marked anterior chamber inflammation (flare values above 150 photons $/ \mathrm{ms}$ ). There were no cases of postoperative iritis in either group requiring a change in the standard topical medication regimen.

\section{Discussion}

In this preliminary study we have shown that subconjunctival betamethasone has no beneficial effect on damage to the $\mathrm{BAB}$ (as measured by the laser flare cell meter) following cataract surgery in uncomplicated eyes. In view of the proved effect of topical steroids given later on in the postoperative period, the most likely reason for this finding is that the effect of subconjunctival Betnesol is short lived and complete within too short a time to influence the later inflammatory consequences of surgery.

Most of the published reports on the kinetics of subconjunctival injections are based on animal studies. Maurice and $\mathrm{Ota}^{5}$ found that following a subconjunctival injection of small volumes of tracers ${ }^{22} \mathrm{Na},{ }^{131} \mathrm{I}$-hippurate, albumin) in the rabbit eye there was rapid loss of the tracer from the subconjunctival space into the blood. The half-life varied from 9 minutes for ${ }^{22} \mathrm{Na}$ and 20 minutes for ${ }^{131} \mathrm{I}$-hippurate to 9 hours for albumin. After 1 hour ${ }^{22} \mathrm{Na}$ was no longer detectable at the injection site and there was little penetration of tracer into the anterior chamber. In the case of ${ }^{22} \mathrm{Na}$ the peak concentration in the aqueous occurred within the first hour, and was only $1 \%$ of the total injected dose. With the larger molecules the peak concentration occurred later and also at a lower percentage of total dose. They concluded that penetration into the aqueous was only possible for a brief period after injection due to the rapid clearance of tracer from the injection site into blood. Wine $e t a l,{ }^{6}$ also using the rabbit, investigated the time course and route of ocular penetration of radio-labelled ${ }^{14} \mathrm{C}$ hydrocortisone from a subconjunctival injection $(0.25 \mathrm{ml}$ of a $2.5 \%$ solution). They found that a peak ocular concentration of hydrocortisone $(176.7 \mu \mathrm{g})$ occurred within 30 minutes of injection with a rapid decline in concentration within 2 hours $(41 \cdot 1 \mu \mathrm{g})$ and a more gradual decline to $1.8 \mu \mathrm{g}$ at 72 hours. If the technique of subconjunctival injection was modified so that the conjunctival surface remained intact the peak concentration was significantly reduced $(3 \cdot 9 \mu \mathrm{g})$. They concluded that the major route of ocular penetration from a subconjunctival injection of hydrocortisone was therefore by leakage through the needle puncture wound into the conjunctival sac and then through the cornea to the anterior chamber by the tear film. However autoradiographic studies in rabbit eyes do indicate that subconjunctival hydrocortisone can penetrate directly through the sclera from the injection depot site. McCartney et $a l^{7}$ found that penetration occurred within 30 minutes in the inflamed eye and only after 4 hours in the normal eye. They also confirmed that only a very small proportion of the drug penetrated into the eye (about $1-2 \%$ ).

It has been assumed in most of the animal studies on this subject that the results are relevant and applicable to humans. However Maurice and Ota ${ }^{5}$ have found marked differences between the rabbit and human eye in the penetration of fluorescein into aqueous from subconjunctival injections, and they have therefore questioned the validity and relevance of results obtained in the rabbit model. There are few reports on the kinetics of subconjunctival injections in humans. They have been carried out on normal eyes and may not reflect the pharmacokinetics in inflamed or postoperative eyes where changes in aqueous flow or leakage may be important. Jain et $a l^{8}$ measured the concentration of both hydrocortisone acetate and dexamethasone sodium phosphate in aqueous humour in normal eyes following subconjunctival injection (dexamethasone $0.5 \mathrm{ml}$ of $0.4 \%$ solution, hydrocortisone $0.5 \mathrm{ml}$ of $2.5 \%$ solution). Peak concentration occurred within 10 minutes; dexamethasone was no longer detectable at 48 hours after injection and although hydrocortisone was detectable at 7 days after injection it was only present in very low concentrations. It would appear from these studies that the penetration of a solution of steroids into aqueous humour from a subconjunctival site is often poor. No information is available about what tissue levels of steroid are effective and a potential therapeutic effect may be over within hours. If postoperative inflammation depends on recruitment of inflammatory cells this may occur too late to be influenced by a perioperative injection. Mechanical trauma at the time of surgery may be the main contributing factor to the extent of damage to the $\mathrm{BAB}$ on the first postoperative day. ${ }^{9}$ Therefore the use of a shortacting anti-inflammatory agent immediately after surgery may be relatively less important than it is in the subsequent days following surgery when a true immunological inflammatory response is likely to be more significant. This would be consistent with clinical studies in which postoperative iritis and particularly fibrinous iritis is reported to occur usually 3-5 days after surgery. ${ }^{1011}$

The absorption of subconjunctival steroids and their therapeutic effect is also affected by the type of steroid used and the vehicle used to deliver it. Betamethasone and dexamethasone have 5-7 times greater systemic antiinflammatory activity than prednisolone on a weight for weight basis. The absorption of these steroids into aqueous following topical application has been shown to be significantly different depending on the vehicle used. McGhee et $a l^{12}$ measured the aqueous concentrations (using gas chromatography with mass spectrometry (GCMS)) of prednisolone acetate (1\%), fluoromethalone alcohol $(0 \cdot 1 \%)$, dexamethasone alcohol $(0 \cdot 1 \%)$, betamethasone sodium phosphate $(0 \cdot 1 \%)$, and prednisolone sodium phosphate $(0.5 \%)$ following single drop instillation. They found a large variation in peak aqueous concentration, ranging from $669.6 \mathrm{ng} / \mathrm{ml}$ with prednisolone acetate, $31.0 \mathrm{ng} / \mathrm{ml}$ with dexamethasone alcohol, $25.6 \mathrm{ng} / \mathrm{ml}$ with prednisolone sodium phosphate, and $7 \cdot 7 \mathrm{ng} / \mathrm{ml}$ with betamethasone sodium phosphate. Acetate and alcohol steroid preparations are lipophilic and penetrate the corneal epithelium better than polar preparations such as sodium salts of the steroid phosphate. The appropriately adjusted 
index of concentration for these steroids (assuming a seven-fold difference in potency between prednisolone and the other steroids) are 95.7 for prednisolone acetate, 31.0 for dexamethasone alcohol, $7 \cdot 7$ for betamethasone sodium phosphate, and 3.3 for prednisolone sodium phosphate. Therefore the use of subconjunctival betamethasone in its sodium phosphate form may also theoretically reduce its absorption and minimise the therapeutic effect. Other types of steroid, more long acting or reservoir preparations may be better suited to perioperative use.

In conclusion we have found in this preliminary study that the use of subconjunctival betamethasone has no beneficial effect on damage to and recovery of the blood aqueous barrier following cataract surgery in otherwise normal eyes. The incidence of postoperative inflammatory complications is greater in diabetics and in eyes with glaucoma and uveitis and similar further studies are required to assess both the role and type of subconjunctival steroids in these high risk groups. We therefore feel that at present the routine use of subconjunctival steroids in cataract surgery is not cost-effective and should be restricted to high risk cases and in those patients who develop operative complications.
This study was supported by charitable funds from The Iris Fund for the Prevention of Blindness, The Star Foundation, and The Andrew Wilson Trust.

1 Miyake K. Fluorophotometric evaluation of the blood ocular barrier function following cataract surgery and intraocular
lens implantation. F Cat Refr Surg 1988;14: 560-8.

2 Sawa $M$, Tsurimaki $Y$, Tsuru T, Shimuzu H. New quantitative method to determine protein concentration and cell number in aqueous in vivo. fpn $^{\prime} \mathcal{F}$ Ophthalmol 1988; 32: 132-42.

3 Shah SM, Spalton DJ, Smith SE. Measurement of aqueous cells and flare in normal eyes. Br $\mathcal{F}$ Ophthalmol 1991; 75: 348-52.

4 Spalton DJ, Shah SM. A comparison of the laser flare cell meter and anterior segment fluorophotometry in the assessment of damage to the blood-aqueous barrier following cataract surgery. ARVO Abstracts, Invest Ophthalmol Vis Sci cataract surgery. ARVO Abstract

5 Maurice DM, Ota Y. The kinetics of subconjunctival injections. Fpn f Ophthalmol 1978; 22: 95-100.

6 Wine N, Gornall AG, Basu PK. The ocular uptake of subconjunctivally injected ${ }^{14} \mathrm{C}$ hydrocortisone. $\mathrm{Am} \mathcal{F}$ Ophthalmol 1964; 58: 362-6.

7 McCartney HJ, Drysdale IO, Gornall AG, Basu PK. An autoradiographic study of the penetration of subconjunctivally injected hydrocortisone into the normal and inflamed tivally injected hydrocortisone into the normal and in

8 Jain MR, Srivastava S. Ocular penetration of hydrocortisone and dexamethasone into the aqueous humour after subconjunctival injection. Trans Ophthalmol Soc UK 1978; 98: 63 5.

9 Ferguson VMJ, Spalton DJ. Continued breakdown of the blood aqueous barrier following cataract surgery. $\mathrm{Br} \mathcal{J}$ Ophthalmol 1992; 76: 453-6.

$10 \mathrm{Nishi} \mathrm{O}$. Fibrinous membrane formation on the posterio chamber lens during the early postoperative period. $\mathcal{f}$ Cataract Refract 1988; 14: 73-7.

11 Olivius E, Nordell S, Walinder P. Fibrinoid reaction after extracapsular cataract extraction and its relationship to exfoliation syndrome - a prospective study. Eur $\mathcal{F}$ Implan Ref 1989; 1: 5-8.

12 McGhee CNJ, Watson DG, Midgley JM, Noble MJ, Dutton GN, Fern AI. Penetration of synthetic corticosteroids into human aqueous humour. Eye 1990; 4: 526-30. 